\title{
O QUE ESPERAR
}

\author{
Theresa AdRIÃO ${ }^{1}$ \\ IVANY RodRIGUES PINO ${ }^{1,2}$ \\ Carmen Sylvia Vidigal Moraes ${ }^{3}$ \\ Antonio Álvaro Soares Zuin ${ }^{4}$ \\ Celso João Ferretti ${ }^{2}$ \\ Luana Costa Almeida ${ }^{4}$ \\ Pedro Goergen ${ }^{5}$ \\ SANDra Maria Zákia Lian SouZa ${ }^{3}$ \\ SAlomão Barros Ximenes ${ }^{6}$ \\ Adriana Dragone Silveira ${ }^{7}$
}

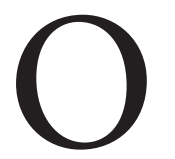

ano de 2020 começa sem perspectivas de superação das dificuldades vivenciadas pela educação e pela ciência durante o ano de 2019 no Brasil. Nomeadamente, dado o impacto direto para a sobrevivência de periódicos científicos e de organizações da sociedade civil, destacamos a manutenção dos cortes orçamentários do governo federal em investimentos para pesquisa; a política, por vezes burlesca, mas na essência permeada por ataques às universidades públicas pelo Ministro da Educação; o desmonte do limitado aparato de defesa dos direitos humanos; o acirramento, em todos os campos, da atmosfera de limitação ao exercício das liberdades; a desqualificação das ciências de maneira geral e, por fim, a ampliação de processos de privatização da política pública, tanto no sentido de subordinação explícita a interesses de grupos específicos, quanto no sentido da transferência da oferta e da gestão de políticas e programas governamentais para atores privados, em muitos casos com subsídio governamental.

Nessa conjuntura, uma organização como o Centro de Estudos Educação e Sociedade (CEDES), cujos principais mecanismos de ação e de reconhecimento acadêmico e científico são suas publicações e os Seminários da Educação Brasileira, não está isenta de impactos, sobretudo diante da atual dificuldade de amealhar recursos para editoração, provenientes de editais de agências de fomento, tal como o CNPq. Em verdade, a dificuldade figura como mais uma estratégia de esvaziamento das Ciências Humanas e Sociais, preocupação que motivou, em abril de 2019, manifestação em carta aberta da Sociedade Brasileira para o Progresso da Ciência (SBPC, 2019) em resposta à ameaça do governo federal de cortar investimentos para as faculdades de filosofia e sociologia. Na oportunidade, a SBPC declarava:

\footnotetext{
1.Universidade Estadual de Campinas - Faculdade de Educação - Campinas (SP), Brasil. E-mail: adriaotheresa@gmail.com; ivanypino@gmail.com

2.Centro de Estudos Educação e Sociedade - Campinas (SP), Brasil. E-mail: ivanypino@gmail.com; celsojoaoferretti@gmail.com

3.Universidade de São Paulo - Faculdade de Educação - São Paulo (SP), Brasil. E-mail: moraescs@usp.br; sanzakia@usp.br 4.Universidade Federal de São Carlos - Departamento de Educação - São Carlos (SP), Brasil. E-mail: dazu@ufscar.br; luana.ees@gmail.com 5.Universidade de Sorocaba - Sorocaba (SP), Brasil. E-mail: pedro.goergen@hotmail.com

6.Universidade Federal do ABC - São Bernardo do Campo (SP), Brasil. E-mail: salomaoximenes@gmail.com

7.Universidade Federal do Paraná - Setor de Educação - Curitiba (PR), Brasil. E-mail: adrianadragonesilveira@gmail.com
} 
Além de possibilitar o avanço do próprio conhecimento da área social, cabe tornar explícita a principal contribuição dessas ciências. Por meio das suas teorias, modelos e metodologias, elas procuram fornecer subsídios para a formulação, implementação, acompanhamento e avaliação das políticas públicas elaboradas pelo governo e pela sociedade, visando à melhoria do bem estar social, que é aferido qualitativa e quantitativamente por meio de indicadores apropriados (SBPC, 2019).

Sublinha-se que, se um país abdica do reconhecimento das ciências humanas como ciências estratégicas para seu desenvolvimento, significa que ele está abrindo mão de si mesmo.

Considerando, especialmente nessa difícil conjuntura, a relevância das ciências humanas e particularmente das ciências da educação, Educação \& Sociedade tem resistido inclusive às dificuldades financeiras para sua publicação mantendo, assim como outros periódicos científicos da educação, a capacidade de propor novas estratégias sem, contudo, abdicar da qualidade, credibilidade e da visibilidade no processo de divulgação da pesquisa em educação. Nessa direção, criou-se, em 2019, uma nova seção denominada Seção Especial. A iniciativa tem por objetivo publicar artigos decorrentes de pesquisas relacionadas a um tema anualmente definido pelos/as editores/as, tendo em vista sua relevância para o estudo e para a análise qualificada de questões concernentes à relação educação e sociedade.

Em 2020 o tema é PRIVATIZAÇÃO da Educação, entendida como os processos pelos quais a educação escolar tem sido transferida para esferas privadas, sejam estas atinentes ao campo dos mercados, sejam relacionadas a atores privados que, em substituição ao dever do Estado, arrogam-se à condição de protagonistas da realização do direito à educação. Na chave de análise de Belfield e Levin (2002, p. 19), privatização é um termo guarda-chuva relativo a diferentes programas e políticas. Em termos gerais, refere-se a processos que transferem as atividades, os ativos e as responsabilidades do governo/instituições públicas para os indivíduos ou agências e organizações privadas. Além disso, a privatização é frequentemente pensada como "liberalização", por meio da qual os países isentam-se de regulamentações governamentais, ou como "mercantilização", quando novos mercados são criados como serviços alternativos aos governamentais. Tendo em vista a chave de análise sugerida, o tema da Seção Especial 2020 busca estimular a divulgação de perspectivas originais para o tratamento da temática.

Em síntese, Educação \& Sociedade convida autores e autoras a submeterem à Seção Especial trabalhos que agreguem novas perspectivas de análise a respeito dos processos, das formas e das estratégias adotadas para a privatização da educação em diferentes contextos. Consideram-se ainda como relevantes análises sobre as políticas das quais derivam, bem como estudos que evidenciem as consequências da privatização para a realização da educação como direito humano e para o enfretamento das desigualdades educacionais. Seguindo as orientações aos autores, os artigos, em demanda contínua, deverão ser submetidos até 31 de julho de 2020 no Sistema SciELO, na Seção Especial. Prevê-se para 2020 a publicação de oito artigos nessa Seção.

A todos e a todas que acompanham e apoiam Educação \& Sociedade, um ano de qualificadas leituras, democráticos diálogos e afirmação do Estado de Direito

\section{Referências}

BELFIELD, C. R.; LEVIN, H. M. Education privatization: causes, consequences, and planning implications. Paris: UNESCO-IIPE, 2002. p. 79. Disponível em: https://unesdoc.unesco.org/ark:/48223/pf0000133075. Acesso em: 02 de fev. de 2020.

Sociedade Brasileira para o Progresso da Ciência (SBPC). SBPC se manifesta em defesa das Ciências Humanas e Sociais: Nota pública da SBPC em defesa das ciências humanas e sociais. São Paulo: SBPC, 2019. Disponível em: http://portal.sbpcnet.org.br/noticias/sbpc-se-manifesta-em-defesa-das-cienciashumanas-e-sociais/. Acesso em: 02 de fev. de 2020. 